\title{
Effective Canadian policy to reduce harms from prescription opioids: learning from past failures
}

\author{
Benedikt Fischer PhD, Jürgen Rehm PhD, Mark Tyndall MD ScD
}

See also page 1208 and www.cmaj.ca/lookup/doi/10.1503/cmaj.160554

Competing interests: None declared.

This article has been peer reviewed.

Correspondence to:

Benedikt Fischer,

benedikt.fischer@camh.ca

CMAJ 2016. DOI:10.1503 /cmaj.160356
$\mathrm{T}$ The use of prescription opioids to treat pain has increased over the past two decades in Canada, but it has led to a major public health crisis. Since 2000, the number of cases of opioid-related misuse, addiction disorders and admissions to hospitals or treatment programs continues to grow. Deaths from opioid overdoses have also risen.

Several authorities have launched interventions, mostly since 2010 , but most have been ad hoc, reactive and limited in scope. These interventions have failed to effectively address the root causes of the opioid crisis. This crisis is only getting worse, and Canada urgently needs to implement effective measures aiming at and addressing the underlying drivers of the opioid epidemic.

\section{A growing crisis}

National surveillance data have been spotty and inconsistent, but data from population surveys showed that, by 2010, more than 1 in 20 adults and as many as one in six adolescents - were using prescription opioids for nonmedical purposes. ${ }^{1}$ In addition, prescription opioids have become highly available and popular drugs on the street, which have also disproportionately affected indigenous and other vulnerable populations. Misuse has become highly prevalent on many reserves in Northern Ontario and elsewhere. ${ }^{1,2}$

\section{KEY POINTS}

- Canada has been facing a major public health crisis of prescription opioid-related morbidity and deaths.

- Several - largely narrow and reactive in scope - interventions have been implemented since 2010, yet, they have remained ineffective in curtailing morbidity and deaths.

- Overall amounts and patterns (e.g., high dose) of prescription opioids dispensed are primary causal drivers of population-level morbidity and mortality.

- Authorities should urgently implement effective (e.g., enforceable guidelines with use/dose restrictions) evidence-based measures to reduce overall amounts of opioid dispensing and thus harms.

Demand for opioid-related addiction treatment has soared. In Ontario, for example, annual admissions to publicly funded (nonpharmacotherapy) treatment for opioid-related problems doubled between 2004 and 2013, from 8799 to $18232 .{ }^{3,4}$ Enrolments in opioid pharmacotherapy also rapidly increased. Based on updated numbers, there were more than 50000 individuals enrolled in methadone treatment in Ontario by 2015, and similar proportional trends were seen in British Columbia. ${ }^{4,5}$

Deaths from opioid-related poisonings have increased too. The annual number of opioidrelated deaths in Ontario, most involving young people, rose from 127 in 1991 to 680 in 2014, which is a greater than fivefold increase. ${ }^{6-8}$ Data for overdose deaths from other provinces indicate similar levels and increases. ${ }^{9,10}$ In 2015, an estimated 2000 Canadians - about 1200 in BC, Alberta and Ontario alone - died from opioidrelated poisonings. Initial numbers for 2016 are higher again, and more deaths are being attributed to clandestinely produced fentanyl and other opioid products. ${ }^{8,10,11}$

\section{Past interventions ineffective}

In the past few years, Canadian authorities have initiated several measures to address the emerging opioid crisis. In 2010, the National Opioid Use Guideline Group presented recommendations for prescribing practices in the Canadian guideline for safe and effective use of opioids. Most of the recommendations were softly phrased suggestions, for example, considering the use of a screening tool, monitoring analgesic effectiveness and trying a different opioid. Yet, almost all recommendations supported prescribing opioids and contained little direction about when not to prescribe or when to limit doses or durations. ${ }^{12}$

In 2012, oxycodone was implicated in a disproportionate number of opioid-related harms and deaths, which prompted several provinces 
to remove it from their drug formularies..$^{13}$ Oxycodone prescribing decreased, but there was a shift to prescribing other potent opioids, mainly fentanyl and hydromorphone. ${ }^{13}$

Some provinces, such as Ontario, recently introduced prescription monitoring systems for narcotic drugs. ${ }^{14}$ However, many existent systems do not operate in real-time and are underused by prescribers. ${ }^{14-17}$ In 2013, a national strategy to provide a "roadmap for reducing the harms associated with [prescription drugs] while giving important consideration to their therapeutic uses" was released and presented a list of (largely complex or vague) recommendations; however, it is not clear how many have been effectively implemented. ${ }^{18}$ Federal regulators presented draft regulations in 2015 to require a tamper-proof design for prescription opioids; however, it was limited to oxycodone formulations only, which accounted for about $10 \%$ of dispensed opioids. ${ }^{13,19}$ Furthermore, evidence that tamper proofing reduces opioid misuse or harms is weak at best. ${ }^{20,21}$

Health authorities in Canada have called for increased availability of naloxone, an opioid antagonist, that federal regulators recently changed from prescription to nonprescription. ${ }^{10}$ They also called for more supervised consumption facilities and opioid-maintenance treatment (mainly buprenorphine/naloxone). ${ }^{10,22,23}$ Overall, these measures have not decisively decreased morbidity and mortality caused by opioid use. Nonmedical prescription opioid use in general populations has subsided somewhat since 2010, but related treatment demand and overdose deaths have continued to increase. ${ }^{4}$

\section{Unaddressed issues}

Evidence of the therapeutic effectiveness of prescription opioids for pain is rather limited. Data show some benefits for treatment of acute pain, but evidence to support using opioids to treat longterm chronic pain is weak and insufficient. ${ }^{24-26}$ Yet, data about the public health impacts clearly indicate that the amounts and patterns of opioid dispensing influence levels of adverse effects in the population: increases in amounts of opioids dispensed are associated with increases in morbidity and mortality. Concretely, epidemiologic studies at the population level in North America have shown strong correlations over time between levels of opioid dispensing and opioid-related deaths (e.g., overdoses), and between levels of morbidity (e.g., visits to the emergency department) and abuse..$^{27-32}$ However, dispensing of prescriptions opioids in Canada has increased steadily since 2000, from 10209 defined daily doses per million population a day in 2001-2003 to 30540 in 2012-2014. ${ }^{19,33}$ Canada has the second highest rate of opioid use in defined daily doses and the highest overall when considering morphine equivalence. ${ }^{19,34}$ By 2010, one in five Canadians had reported the use of pain relievers in the previous year. ${ }^{35}$ Most increases in use have been in strong opioid formulations with high potential for adverse effects, including fentanyl and hydromorphone. ${ }^{13,19}$

In addition to patterns, high-dose dispensing of opioids is a practice strongly associated with elevated risk of adverse outcomes. For example, a population-based nested case-control study in Ontario showed that, relative to low doses of less than $20 \mathrm{mg}$ of morphine equivalents daily, higher opioid doses were consistently associated with increased rates of fatal poisoning, with a nearly threefold increased risk of death in the highest dosage range (> $200 \mathrm{mg} / \mathrm{d}$ ). ${ }^{36}$ Similarly, in a study involving a cohort of veterans in the United States (20042008), the risk of death following overdose was directly related to the maximum prescribed daily opioid dose ( $\geq 100 \mathrm{mg}){ }^{37,38}$ Despite these risks, a population-based cross-sectional study showed that the rate of high-dose opioid dispensing in Canada increased $23 \%$ from 781 units per 1000 population in 2006 to 961 per 1000 population in $2011 .{ }^{39}$ Similarly, among those enrolled in the Ontario Drug Benefit plan, the daily opioid dose dispensed in 2008 exceeded $200 \mathrm{mg}$ morphine equivalents for one-third of those prescribed long-acting oxycodone and $20 \%$ of those receiving fentanyl or other long-acting opioids. ${ }^{40}$

In this increasingly opioid-saturated environment in Canada, increasing quantities of opioids have been available for diversion and misuse. Although aggressive marketing efforts by pharmaceutical companies and training deficiencies among medical professionals may have contributed in general to these steep increases, ${ }^{41,42}$ they occurred in regulatory environments that permitted such developments. It appears that the various interventions implemented in Canada were neither designed nor capable in their predominantly narrow and reactive scope to curtail these primary drivers of prescription opioidrelated harms. The amounts of opioids dispensed and high dosing were not reduced to more sensible levels; consequently, opioidrelated harms continued to rise.

\section{Evidence from abroad}

Select experiences from other jurisdictions suggest that tighter restrictions on opioid prescribing in Canada likely would have prevented extensive 
opioid-related harms more effectively. ${ }^{43}$ Western European countries have similar pain prevalence levels, and, although opioid-dispensing rates there have also increased in recent years, they are still considerably lower than in Canada. These countries also have a variety of regulatory restrictions in place for prescribing and dispensing (i.e., restrictions on dosages and amounts, settings where opioids can be dispensed and which physicians are authorized to prescribe them).$^{44}$ For example, prescriptions for opioids in Germany require specific forms and are limited in dosing; only about 1 in 20 insured persons received an opioid prescription in 2010.45 Japan - one of the most developed industrialized nations - has a prescription opioid use rate (in defined daily doses) of less than 5\% compared with Canada. ${ }^{19}$ Although opioids are generally available and concerns about undertreatment of pain exist, alternative approaches and tools for the treatment of chronic pain are emphasized, with substantially lower quantities of opioids prescribed. ${ }^{46-48}$

Overall, medical system culture - including less commercialization in health care and less influence from the pharmaceutical industry and advertising - has been found to play a role in differentiating levels of opioid use in different contexts: some practices rely less on pharmacotherapy to deal with pain. ${ }^{49,50}$ Consequently, opioid-related harms as observed in North America are considered uncommon elsewhere (e.g., in Europe). ${ }^{45}$

Valuable lessons can also be learned from the US, where rates of opioid use and its associated harms have been among the world's highest. $^{51,52}$ Over the last few years, there were about 488000 emergency department visits related to prescription opioids, 155000 treatment admissions and 18000 fatal poisonings annually, the latter contributing to unprecedented life-expectancy reductions for white middle-aged Americans. ${ }^{53-56}$ However, there has been increasing recognition of the essential relationship between opioid dispensing and harm levels, and its importance for effective upstream measures for reducing prescribing amounts and risks. In April 2016, the Centers for Disease Control and Prevention published the guideline for prescribing opioids for chronic pain featuring clearly articulated recommendations to use nonpharmacologic or nonopioid pharmacologic treatment for chronic pain, to prescribe immediate-release opioids instead of long-acting extended-release opioids and to seek the lowest effective dosage to address "pain severe enough to require opioids." ${ }^{57}$ In addition, the guideline recommended regular evaluation of the benefits and harms of opioid therapy in the patient, and to avoid prescribing opioids and benzodiazepines concurrently..$^{57,58}$

Other measures implemented in other US jurisdictions have included high-dose limits for opioids, which have resulted in marked declines in opioid deaths (e.g., in Washington State). ${ }^{59,60}$ In Florida, tighter restrictions on opioid prescribers combined with law-enforcement clampdowns have substantially reduced overall amounts of opioid prescribing, diversion and deaths. ${ }^{61,62}$ In regions of North Carolina, intensive physician education combined with emergency measures have resulted in decreased mortality. ${ }^{63}$ Although the US has a long way to go to reverse its opioid public health crisis, the amounts of opioids dispensed nationally have plateaued, and levels of key adverse events have seen initial reductions, at least in some regions. ${ }^{64}$

\section{A solution for Canada}

To reduce the opioid-related toll on public health, medical regulators in Canada ought to devise effective upstream interventions to reduce the excessive levels and hazardous patterns of opioid prescribing based on available evidence. ${ }^{65,66}$ This should involve clear formulation of enforceable guidelines with the aim to have opioids prescribed only in cases supported by good scientific evidence and to be considered an exceptional treatment. Opioids should be dispensed in the lowest possible dose and for the shortest possible duration. ${ }^{24,25,57,67}$ Similar measures have been implemented recently in $\mathrm{BC}$, which adopted the $\mathrm{CDC}$ guideline as a professional standard, and also in Nova Scotia. ${ }^{68,69}$ These measures may reduce excessive levels and hazardous patterns of opioid dispensing and associated adverse events, such as poisoning deaths, and should be implemented expediently across the country.

Ontario recently announced a set of policy measures aimed at reducing opioid harms that includes standards for opioid prescribing (to be released), the delisting of high-strength opioid formulations from the provincial formulary, and increased access to pharmacotherapy with buprenorphine/naloxone and naloxone availability. ${ }^{70,71}$ The effects of these measures will need to be evaluated rigorously.

Standardized, real-time, electronic prescription monitoring systems for opioids should be established across the country, and medical professionals should be required to consult them before prescribing or dispensing opioids. Although the evidence is inconclusive on whether prescription monitoring systems reduce opioid-related 
harms, ${ }^{72,73}$ there is stronger support for beneficial effects from "superior" programs (those with direct data feeds to providers), which are only provided in a few places in Canada. ${ }^{17}$

A comprehensive action plan will need to provide for increased availability of evidencebased treatment, including both pharmacotherapeutic and nonpharmacotherapeutic options, for opioid-related disorders and measures to prevent death, such as naloxone provision and supervised consumption services. ${ }^{5,67,73-75}$ These measures surely will not solve the fundamental causes of the prescription opioid problem, but will reduce some of its acute and long-term consequences, including extensive morbidity (e.g., the large number of individuals with prescription opioid-related disorders) and overdose deaths.

Finally, Canada should establish an appropriate national surveillance system for opioidrelated harm indicators — such as emergency, treatment and overdose death episodes — as is standard elsewhere. ${ }^{55,56,76,77}$

It is late - but not too late - to move toward reducing the toll of opioid overuse and abuse in Canada.

\section{References}

1. Fischer B, Argento E. Prescription opioid related misuse, harms, diversion and interventions in Canada: a review. Pain Physician 2012;15(Suppl):ES191-203.

2. Fischer B, Rehm J, Patra J, et al. Changes in illicit opioid use profiles across Canada. CMAJ 2006;175:1385-7.

3. Fischer B, Nakamura N, Rush B, et al. Changes in and characteristics of admissions to treatment related to problematic prescription opioid use in Ontario, 2004-2009. Drug Alcohol Depend 2010; 109:257-60

4. Murphy Y, Goldner EM, Fischer B. Prescription opioid use, harms and interventions in Canada: a review update of new developments and findings since 2010. Pain Physician 2015;18 E605-14.

5. Fischer B, Kurdyak P, Goldner E, et al. Treatment of prescription opioid disorders in Canada: looking at the 'other epidemic'? Subst Abuse Treat Prev Policy 2016;11:12.

6. Dhalla IA, Mamdani MM, Sivilotti ML, et al. Prescribing of opioid analgesics and related mortality before and after the introduction of long-acting oxycodone. CMAJ 2009;181:891-6.

7. Gomes T, Mamdani MM, Dhalla IA, et al. The burden of premature opioid-related mortality. Addiction 2014;109:1482-8.

8. Woo A, Howlett K. Fentanyl now leading cause of opioid deaths in Ontario. The Globe and Mail [Toronto]; 2016 Feb. 21. Available: www.theglobeandmail.com/news/national/fentanyl -now-leading-cause-of-opioid-deaths-in-ontario/article28832627/ (accessed 2016 Mar. 18).

9. Gladstone EJ, Smolina K, Morgan SG. Trends and sex differences in prescription opioid deaths in British Columbia, Canada. Inj Prev 2016;22:288-90.

10. Southwick R. Fentanyl death toll hits 270 in Alberta, sowing destruction in families of many demographics. Calgary Herald 2016. Available: http://calgaryherald.com/news/local-news/fentanyl -death-toll-hits-270-in-alberta-sewing-destruction-in-families-of-alldemographics (accessed 2016 Oct. 19).

11. Baker P. Accidental drug overdoses still climbing in B.C. in 2016: Coroner. Global News 2016. Available: http://globalnews. ca/news/2890915/accidental-drug-overdoses-still-climbing-in-b-c -in-2016-coroner/ (accessed 2016 Oct. 19)

12. Canadian guideline for safe and effective use of opioids for chronic non-cancer pain. Hamilton (ON): National Opioid Use Guideline Group (NOUGG); 2010.

13. Fischer B, Jones W, Rehm J. Trends and changes in prescription opioid analgesic dispensing in Canada 2005-2012: an update with a focus on recent interventions. BMC Health Serv Res 2014; $14: 90$
14. Gomes T, Juurlink D, Yao Z, et al. Impact of legislation and a prescription monitoring program on the prevalence of potentially inappropriate prescriptions for monitored drugs in Ontario: a time series analysis. CMAJ Open 2014;2:E256-61.

15. Together we can do this: strategies to address British Columbia's prescription opioid crisis - recommendations from the British Columbia node of the Canadian Research Initiative on Substance Misuse. Vancouver: British Columbia Centre for Excellence in HIV/AIDS (BCCFE) and Ottawa: Canadian Institutes of Health Research (CIHR); 2015.

16. Paulozzi LJ, Kilbourne EM, Desai HA. Prescription drug monitoring programs and death rates from drug overdose. Pain Med 2011;12:747-54.

17. Furlan AD, MacDougall P, Pellerin D, et al. Overview of four prescription monitoring/review programs in Canada. Pain Res Manag 2014;19:102-6.

18. First do no harm: responding to Canada's prescription drug crisis: annual report 2013-2014. Ottawa: Canadian Centre on Substance Abuse; 2014.

19. International Narcotics Control Board (INCB). Narcotic drugs: estimated world requirements for 2016, statistics for 2014. Vienna (Austria): United Nations; 2015.

20. Leece P, Orkin AM, Kahan M. Tamper-resistant drugs cannot solve the opioid crisis. CMAJ 2015;187:717-8

21. Mastropietro DJ, Omidian H. Current approaches in tamperresistant and abuse-deterrent formulations. Drug Dev Ind Pharm 2013;39:611-24

22. Dhillon S, Howlett K. BC declares public health emergency as overdoses surge again. The Globe and Mail [Toronto]. 2016; Apr. 14. Available: www.theglobeandmail.com/news/british-columbia/ overdoses-prompt-bc-to-declare-public-health-emergency/article 29631552/ (accessed 2016 May 3).

23. Lindeman T. Naloxone, safe injection sites could curb overdoses in Quebec. CBC News. 2014; July 2. Available: www.cbc.ca/m/ touch/canada/montreal/story/1.2692527 (accessed 2016 July 6).

24. Chou R, Turner JA, Devine EB, et al. The effectiveness and risks of long-term opioid therapy for chronic pain: a systematic review for a National Institutes of Health Pathways to Prevention workshop. Ann Intern Med 2015;162:276-86.

25. Franklin GM; American Academy of Neurology. Opioids for chronic noncancer pain: a position paper of the American academy of neurology. Neurology 2014;83:1277-84.

26. Manchikanti L, Ailinani H, Koyyalagunta D, et al. A systematic review of randomized trials of long-term opioid management for chronic non-cancer pain. Pain Physician 2011;14:91-121.

27. Bohnert AS, Ilgen MA, Trafton JA, et al. Trends and regional variation in opioid overdose mortality among veterans health administration patients, fiscal year 2001 to 2009. Clin J Pain 2014;30:605-12

28. Fischer B, Jones W, Rehm J. High correlations between levels of consumption and mortality related to strong prescription opioid analgesics in British Columbia and Ontario, 2005-2009. Pharmacoepidemiol Drug Saf 2013;22:438-42.

29. Dhalla IA, Mamdani MM, Gomes T, et al. Clustering of opioid prescribing and opioid-related mortality among family physicians in Ontario. Can Fam Physician 2011:57:e92-6.

30. Cicero TJ, Surratt H, Inciardi JA, et al. Relationship between therapeutic use and abuse of opioid analgesics in rural, suburban, and urban locations in the United States. Pharmacoepidemiol Drug Saf 2007;16:827-40.

31. Wisniewski AM, Purdy CH, Blondell RD. The epidemiologic association between opioid prescribing, non-medical use, and emergency department visits. J Addict Dis 2008;27:1-11.

32. Modarai F, Mack K, Hicks P, et al. Relationship of opioid prescription sales and overdoses, North Carolina. Drug Alcohol Depend 2013;132:81-6.

33. International Narcotics Control Board. Narcotic drugs: estimated world requirements for 2004, statistics for 2002. New York: United Nations; 2004. Report no.: E/F/S.04.XI.2.

34. International Narcotics Control Board (INCB). Availability of internationally controlled drugs: ensuring adequate access for medical and scientific purposes. New York: United Nations; 2016.

35. Canadian alcohol and drug use monitoring survey (CADUMS): summary of results for 2011. Ottawa: Health Canada; 2012. Available: www.hc-sc.gc.ca/hc-ps/drugs-drogues/stat/_2011/ summary-sommaire-eng.php (accessed 2016 July 6).

36. Gomes T, Mamdani MM, Dhalla IA, et al. Opioid dose and drug-related mortality in patients with nonmalignant pain. Arch Intern Med 2011;171:686-91.

37. Bohnert ASB, Valenstein M, Bair MJ, et al. Association between opioid prescribing patterns and opioid overdose-related deaths. JAMA 2011;305:1315-21.

38. King NB, Fraser V, Boikos C, et al. Determinants of increased opioid-related mortality in the United States and Canada, 1990- 
2013: a systematic review. Am J Public Health 2014;104:E32-42.

39. Gomes T, Mamdani MM, Paterson JM, et al. Trends in highdose opioid prescribing in Canada. Can Fam Physician 2014; 60:826-32.

40. Gomes T, Juurlink DN, Dhalla IA, et al. Trends in opioid use and dosing among socio-economically disadvantaged patients. Open Med 2011;5:e13-22.

41. Van Zee A. The promotion and marketing of OxyContin: commercial triumph, public health tragedy. Am J Public Health 2009;99:221-7.

42. Wenghofer EF, Wilson L, Kahan M, et al. Survey of Ontario primary care physicians' experiences with opioid prescribing. Can Fam Physician 2011;57:324-32.

43. Kotecha MK, Sites BD. Pain policy and abuse of prescription opioids in the USA: a cautionary tale for Europe. Anaesthesia 2013;68:1210-5.

44. Cherny NI, Baselga J, de Conno F, et al. Formulary availability and regulatory barriers to accessibility of opioids for cancer pain in Europe: a report from the ESMO/EAPC opioid policy initiative. Ann Oncol 2010;21:615-26.

45. van Amsterdam J, van den Brink W. The misuse of prescription opioids: A threat for Europe? Curr Drug Abuse Rev 2015;8:3-14.

46. Akiyama M, Takebayashi T, Morita T, et al. Knowledge, beliefs, and concerns about opioids, palliative care, and homecare of advanced cancer patients: a nationwide survey in Japan. Support Care Cancer 2012;20:923-31.

47. Cleary J, Radbruch L, Torode J, et al. Formulary availability and regulatory barriers to accessibility of opioids for cancer pain in Asia: a report from the global opioid policy initiative (GOPI). Ann Oncol 2013;24(Suppl 11):xi24-32.

48. Kitahara M, Kojima KK, Ohmura A. Efficacy of interdisciplinary treatment for chronic nonmalignant pain patients in Japan. Clin J Pain 2006;22:647-55.

49. Fischer B, Keates A, Buhringer G, et al. Non-medical use of prescription opioids and prescription opioid-related harms: Why so markedly higher in North America compared to the rest of the world? Addiction 2014;109:177-81

50. Weisberg D, Stannard C. Lost in translation? Learning from the opioid epidemic in the USA. Anaesthesia 2013;68:1215-9.

51. Manchikanti L, Helm S, Fellows B, et al. Opioid epidemic in the United States. Pain Physician 2012;15(Suppl):ES9-38.

52. Volkow ND, Frieden TR, Hyde PS, et al. Medication-assisted therapies-tackling the opioid-overdose epidemic. $N$ Engl J Med 2014;370:2063-6.

53. Case A, Deaton A. Rising morbidity and mortalityin midlife among white non-Hispanic Americans in the 21st century. Proc Natl Acad Sci USA 2015;112:15078-83.

54. Number and age-adjusted rates of drug-poisoning deaths involving opioid analgesics and heroin: United States, 2000 2014. Atlanta (GA): Centers for Disease Control and Prevention, National Centre for Health Statistics; 2015.

55. Treatment episode data set (TEDS): 2003-2013. National admissions to substance abuse treatment services. Rockville (MD): Substance Abuse and Mental Health Services Administration (SAMHSA); 2015. Report no.: BHSIS Series S-75, HHS Publication No. (SMA) 15-4934

56. Drug abuse warning network, 2011. National estimates of drugrelated emergency department visits. Rockville (MD): Substance Abuse and Mental Health Services Administration; 2013. Report no.: DAWN Series D-39, HHS Publication No. (SMA) 13-4760.

57. Dowell D, Haegerich TM, Chou R. CDC guideline for prescribing opioids for chronic pain — United States, 2016. MMWR Recomm Rep 2016;65:1-49.

58. Olsen $\mathrm{Y}$. The $\mathrm{CDC}$ guideline on opioid prescribing: rising to the challenge. JAMA 2016;315:1577-9.

59. Franklin GM, Mai J, Turner J, et al. Bending the prescription opioid dosing and mortality curves: impact of the Washington state opioid dosing guideline. Am J Ind Med 2012;55:325-31.

60. Garg RK, Fulton-Kehoe D, Turner JA, et al. Changes in opioid prescribing for Washington workers' compensation claimants after implementation of an opioid dosing guideline for chronic noncancer pain: 2004 to 2010. J Pain 2013;14:1620-8.

61. Johnson H, Paulozzi L, Porucznik C, et al. Decline in drug overdose deaths after state policy changes - Florida, 2010-2012. MMWR Morb Mortal Wkly Rep 2014;63:569-74.
62. Surratt HL, O'Grady C, Kurtz SP, et al. Reductions in prescription opioid diversion following recent legislative interventions in Florida. Pharmacoepidemiol Drug Saf 2014;23:314-20.

63. Albert S, Brason FW II, Sanford CK, et al. Project Lazarus: community-based overdose prevention in rural North Carolina. Pain Med 2011;12(Suppl 2):S77-85.

64. Dart RC, Surratt HL, Cicero TJ, et al. Trends in opioid analgesic abuse and mortality in the United States. N Engl J Med 2015; 372:241-8.

65. Kolodny A, Courtwright DT, Hwang CS, et al. The prescription opioid and heroin crisis: a public health approach to an epidemic of addiction. Annu Rev Public Health 2015;36:559-74.

66. Dhalla IA, Persaud N, Juurlink DN. Facing up to the prescription opioid crisis. BMJ 2011;343:d5142.

67. Volkow ND, McLellan AT. Opioid abuse in chronic pain - misconceptions and mitigation strategies. N Engl J Med 2016;374: 1253-63

68. College board adopts new professional standard on safe prescribing to address public health emergency related to opioid overdoses [news release]. Vancouver: College of Physicians and Surgeons of British Columbia; 2016.

69. College endorses the US Centres for Disease Control and Prevention's guidelines for prescribing opioids for chronic pain [news release]. Halifax (NS): College of Physicians and Surgeons of Nova Scotia; 2016.

70. Dyer O. Ontario plans to stop funding high dose opioids. BMJ 2016;354:i4300

71. Ontario taking action to prevent opioid abuse: province enhancing reporting system, connecting patients with high quality treatment [news release]. Toronto: Ministry of Health and Long Term Care Ontario; 2016.

72. Reifler LM, Droz D, Bailey JE, et al. Do prescription monitoring programs impact state trends in opioid abuse/misuse? Pain Med 2012;13:434-42

73. Haegerich TM, Paulozzi LJ, Manns BJ, et al. What we know, and don't know, about the impact of state policy and systemslevel interventions on prescription drug overdose. Drug Alcohol Depend 2014;145:34-47.

74. Nielsen S, Larance B, Degenhardt L, et al. Opioid agonist treatment for pharmaceutical opioid dependent people. Cochrane Database Syst Rev 2016;(5):CD011117.

75. Clark AK, Wilder CM, Winstanley EL. A systematic review of community opioid overdose prevention and naloxone distribution programs. J Addict Med 2014;8:153-63.

76. Paulozzi LJ, Mack KA, Hockenberry JM; Division of Unintentional Injury Prevention, National Center for Injury Prevention and Control, CDC. Vital signs: variation among states in prescribing of opioid pain relievers and benzodiazepines - United States, 2012. MMWR Morb Mortal Wkly Rep 2014;63:563-8.

77. Fischer B, Gooch J, Goldman B, et al. Non-medical prescription opioid use, prescription opioid-related harms and public health in Canada: an update 5 years later. Can J Public Health 2014;105: E146-9.

Affiliations: Institute for Mental Health Policy Research, Centre for Addiction and Mental Health (Fischer, Rehm); Department of Psychiatry (Fischer, Rehm), University of Toronto; Institute of Medical Science, Faculty of Medicine (Fischer, Rehm), University of Toronto; Dalla Lana School of Public Health (Rehm), University of Toronto, Toronto, Ont.; Department of Medicine (Tyndall), Faculty of Medicine, The University of British Columbia; BC Centre for Disease Control (Tyndall), Vancouver, BC

Contributors: All of the authors made substantial contributions to the conception and design of the work, revised it crticially for important intellectual content, gave final approval of the version to be published and agreed to act as guarantors of the work.

Funding: The authors acknowledge funding support for the present work through Canadian Institutes of Health Research grants SMN-139150 and FRN-94814. 